Eur J Clin Chem Clin Biochem

1995; 33:11-14

(c) 1995 Walter de Gruyter \& Co. Berlin - New York

\title{
Profile of Serum Cholinesterase in Systemic Sepsis Syndrome (Septic Shock) in Intensive Care Unit Patients
}

\author{
By A.S. Al-Kassab ${ }^{1}$ and E. Vijayakumar ${ }^{2}$ \\ 1 Department of Clinical Biochemistry \\ 2 Department of Anaesthesiology \\ College of Medicine, Abha, Saudi Arabia
}

(Received June 1, 1993/September 22, 1994)

\begin{abstract}
Summary: Serum cholinesterase catalytic concentrations were estimated in 26 patients diagnosed as having systemic sepsis syndrome (septic shock) in the Intensive Care Unit (12 were admitted with the diagnosis of systemic sepsis syndrome while 14 patients developed the syndrome while in the unit) and in 66 normal, healthy subjects. The assay was performed for 7 consecutive days in the patient group. There was a very significant decrease in the level of cholinesterase in the patient group from the onset of the study as compared to the control group $(P<0.00001)$. This decrease remained during the course of the seven day study period, indicating hepatic dysfunction early in the diagnosis. When compared to other conventional liver function tests, serum cholinesterase seems to change earlier on in the diagnosis. Prothrombin time showed a pattern of change similar to that of serum cholinesterase. There was a significant relationship between the catalytic concentration of serum cholinesterase and the outcome of the systemic sepsis syndrome, the level being significantly lower in patients who died in comparison to those who lived. It seems that serum cholinesterase is a sensitive indicator of hepatic dysfunction in the systemic sepsis syndrome.
\end{abstract}

\section{Introduction}

Septic shock is being diagnosed increasingly frequently partly due to a greater awareness of this condition and partly due to an actual increase in its incidence in recent years. In spite of rapid advances in laboratory techniques and clinical pharmacology, the initial diagnosis remains a clinical one and antibiotic therapy is essentially empiric. To the practising clinician, systemic sepsis is a diagnostic challenge and a therapeutic dilemma. Hepatic dysfunction represents a major and often life-threatening feature of this sepsis syndrome. Despite the availability of various enzymological assays for liver disease, no satisfactory marker of early hepatic dysfunction in the sepsis syndrome exists.

Serum cholinesterase (EC 3.1.1.8) is an important lipoprotein enzyme synthesized by the liver. This enzyme is capable of hydrolysis of succinylcholine and ester-linked local anaesthetics such as procaine. Estimation of cho- linesterase in serum has been previously used as an index of nutritional status and biosynthetic function of the liver (1), and as a marker of life-threatening cocaine intoxication (2). In addition, it has also been used as a sensitive index of serious organophosphorous poisoning (3).

This study was undertaken to evaluate the diagnostic usefulness of serial determination of serum cholinesterase in patients with the clinical diagnosis of sepsis syndrome admitted to the Intensive Care Unit (ICU). The objective was to study the value of this marker as an indicator of hepatic dysfunction in systemic sepsis. In addition, we attempted to correlate the catalytic concentration of serum cholinesterase and the outcome of treatment in patients with sepsis.

\section{Patients and Methods}

Adult patients admitted to the multidisciplinary Intensive Care Unit at the Asir Central Hospital in Abha, Saudi Arabia were included 
in this study. Patients admitted with a diagnosis of systemic sepsis (12 patients) were enrolled in the study after obtaining the appropriate informed consent. In addition. patients who developed the sepsis syndrome while in the Intensive Care Unit (14 patients) were also included in the study. The study ivas approved by our local hospital ethical committee. The severity of the clinical condition was assessed by the APACHE II scoring system (4) upon admission or upon diagnosis of sepsis syndrome. All patients in this study were Saudi Arabian nationals. The mean age of patients was 54.6 years (range 21-99 years). There was a total of 26 patients in the study group ( 9 males and 17 females).

Patient who had known pre-existing hypoproteinaemia or hypoalbuminaemia, undernutrition, pregnancy, and myxoedema were all excluded from the study. Similarly, patients receiving anti-neoplastic drugs, phenothiazines, cimetidine, or procainamide were also excluded from the study. All these conditions are known to increase the serum catalytic concentration of cholinesterase (5). In addition, patients receiving blood transfusion (but not blood substituents) were excluded from the study. All patients with any clinical or biochemical evidence of pre-existing liver disease were excluded from the study.

The sepsis syndrome (6) in this study was defined according to the criteria of Hammerschmidt et al. (7). The clinical entity was considered to be present when two or more of the criteria from group (A) and any one criterion from group (B) were observed in a patient belonging to a high risk category.

In brief, Group $A$ criteria were defined as:

1. Rectal temperature above $39^{\circ} \mathrm{C}$ or below $36^{\circ} \mathrm{C}$

2. Leukocyte count above $12 \times 10^{9} / 1$ or less than $3 \times 10^{9} / 1$.

3. Differential count showing $>10 \%$ immature granulocytes.

4. Blood culture positive for pathogens.

5. Known or suspected local source of infection with a positive culture for a pathogen.

Group B criteria were defined as:

1. Persistent metabolic acidosis with a standard base excess $<5 \mathrm{mmol} / \mathrm{l}$.

2. Systemic vascular resistance $<800$ dynes/S in patients with a pulmonary artery catheter.

3. Otherwise unexplained hypotension with systolic blood pressure $<90 \mathrm{~mm} \mathrm{Hg}$ for over 2 hours.

The presence of any unexplained deterioration of haemodynamic, respiratory, neurologic, renal, or coagulation quantities was considered strongly corroborative.

Blood samples were obtained by sterile technique using a fresh venipuncture site each time. The blood was split into two tubes, one plain tube for serum collection, and the other a lithium heparin tube for plasma collection. The plasma sample was assayed for general chemistry using an automated analyzer (Hitachi 704 system, Boehringer Mannheim, Germany). The serum was stored at $-20^{\circ} \mathrm{C}$ for subsequent cholinesterase assay. This latter assay was performed in batches and the samples were stored for a maxinum of 8 weeks. Serum cholinesterase was assayed using a Hitachi 704 analyzer utilizing the method of Dietz et al. (8) as modified by den Blaauwen et al. (9). The assay was performed at $30^{\circ} \mathrm{C}$. Samples showing values greater than $12000 \mathrm{U} / \mathrm{l}$ were diluted with 2 volumes of normal saline prior to assay (as suggested by the manufacturer). Controls were included (both high and low). The intra-assay variation was $3 \%$ while the inter-assay variation was $7 \%$.

The following constituents were assayed on the collected blood samples once the clinical diagnosis was made: complete blood count, sodium, potassium, urea, creatinine, liver function tests including alanine aminotransferase, aspartate aminotransferase, alkaline phosphatase, total protein, albumin, prothrombin and activated partial thromboplastin times. In addition, serum cholinesterase was also estimated as described above. Blood samples were drawn daily thereafter for the estimation of the above quantities (whenever possible) up to the first seven days or until the time of the patient's discharge or death, whichever was earlier. A positive blood culture was not considered necessary for inclusion in this study. However, blood was collected aseptically for aerobic and anaerobic culture on day 1 and as appropriate thereafter as a part of the routine Intensive Care Unit protocol.

Blood was also collected from 66 apparently healthy age and sex matched normal controls to establish the baseline values for serum cholinesterase in the local population. Nond of the control patients had known hepatic disease, undernutrition, obesity, myxoedema or pregnancy.

Statistical analysis was performed using the SPSS/PC statistical package loaded onto a personal computer. Since most of the quantities had non-parametric distribution, the Mann-Whitney U test was used for statistical evaluation. When the specific quantity had a normal distribution, the Student t-test was used.

\section{Results}

Table 1 summarizes the results of the comparison of the catalytic concentration of serial serum cholinesterase obtained from the patient group at the entry of the study on day 1 as compared to the control group. Twelve patients in the study were admitted with the diagnosis of sepsis syndrome and 14 patients developed the sepsis while in the Intensive Care Unit. In the first group, the mean APACHE II score was $26.3 \pm 3.46$ while in the second group the mean APACHE II score upon diagnosis was $29 \pm 4.90$. There was a very significant difference $(P<0.00001)$ between the patient group and the control group with serum cholinesterase catalytic concentrations being greatly depressed in the patient group in relation to the control group. This depression was noted throughout the remaining six days of sampling. It should be noted that approximately $20 \%$ of patients in each of the seven study days showed a cholinesterase catalytic concentration within the "normal range". It was

Tab. I Comparison between the catalytic concentration of serum cholinesterase in each day of the study and the control value. Values represent median (range).

\begin{tabular}{|c|c|c|c|c|c|c|}
\hline & \multirow[t]{2}{*}{ Day } & \multirow{2}{*}{$\begin{array}{l}\mathrm{Pa}- \\
\text { ti- } \\
\text { ent } \\
\text { No. }\end{array}$} & \multicolumn{2}{|c|}{$\begin{array}{l}\text { Cholinesterase } \\
\text { (U/1) }\end{array}$} & \multirow{2}{*}{$\begin{array}{l}\text { No. } \\
\text { with } \\
\text { normal } \\
\text { cholin- } \\
\text { esterase }\end{array}$} & \multirow{2}{*}{$\begin{array}{l}\text { p* } \\
\text { value }\end{array}$} \\
\hline & & & $\begin{array}{l}\text { Me- } \\
\text { dian }\end{array}$ & (Range) & & \\
\hline \multirow{7}{*}{$\begin{array}{l}\text { Pati- } \\
\text { ents }\end{array}$} & 1 & 26 & 1877 & $(512-9744)$ & 4 & $<0.00001$ \\
\hline & 2 & 26 & 1650 & $(380-3688)$ & 4 & \\
\hline & 3 & 26 & 2508 & $(332-8244)$ & 4 & \\
\hline & 4 & 15 & 2760 & $(760-6180)$ & 3 & \\
\hline & 5 & 13 & 3162 & $(1488-6752)$ & 2 & \\
\hline & 6 & 12 & 3176 & $(1760-6268)$ & 2 & \\
\hline & 7 & 12 & 2740 & $(1064-7108)$ & 2 & \\
\hline $\begin{array}{l}\text { Con- } \\
\text { trols }\end{array}$ & & 66 & 7216 & $(4123-14748)$ & & \\
\hline
\end{tabular}

* P value was obtained by comparison between each day value and the controls using the Mann-Whitney U test.

The normal range for cholinesterase level was arbitrarily chosen to be $7216 \pm 1000 \mathrm{U} / \mathrm{l}$. 
Tab. 2 Summary of values of selected indices of liver function at oách day of the study. Median (range) is given

\begin{tabular}{|c|c|c|c|c|c|}
\hline Day & $\begin{array}{l}\text { Alanine } \\
\text { aminotransferase } \\
(U / 1)\end{array}$ & $\begin{array}{l}\text { Cholinesterase } \\
(\mathrm{U} / \mathrm{l})\end{array}$ & $\begin{array}{l}\text { Prothrombin } \\
\text { time } \\
\text { (s) }\end{array}$ & $\begin{array}{l}\text { Alkaline } \\
\text { phosphatase } \\
\text { (U/l) }\end{array}$ & No. \\
\hline 1 & $\begin{array}{l}37.5 \\
(11-382)\end{array}$ & $\begin{array}{l}1877 \\
(512-9744)\end{array}$ & $\begin{array}{l}16 \\
(12-48)\end{array}$ & $\begin{array}{l}104 \\
(20-615)\end{array}$ & 26 \\
\hline 2 & $\begin{array}{l}35.5 \\
(9-216)\end{array}$ & $\begin{array}{l}1650 \\
(380-714)\end{array}$ & $\begin{array}{l}17 \\
(12-28)\end{array}$ & $\begin{array}{l}81 \\
(32-645)\end{array}$ & 26 \\
\hline 3 & $\begin{array}{l}30.0 \\
(10-216)\end{array}$ & $\begin{array}{l}2508 \\
(422-8244)\end{array}$ & $\begin{array}{l}16 \\
(13-52)\end{array}$ & $\begin{array}{l}87 \\
(49-196)\end{array}$ & 26 \\
\hline 4 & $\begin{array}{l}32.0 \\
(10-182)\end{array}$ & $\begin{array}{l}2760 \\
(760-6168)\end{array}$ & $\begin{array}{l}15 \\
(13-24)\end{array}$ & $\begin{array}{l}136 \\
(52-350)\end{array}$ & 15 \\
\hline 5 & $\begin{array}{l}23.0 \\
(9-366)\end{array}$ & $\begin{array}{l}3162 \\
(1488-6752)\end{array}$ & $\begin{array}{l}15 \\
(13-27)\end{array}$ & $\begin{array}{l}131 \\
(48-341)\end{array}$ & 13 \\
\hline 6 & $\begin{array}{l}27 \\
(8-199)\end{array}$ & $\begin{array}{l}3176 \\
(1760-6268)\end{array}$ & $(13-27)$ & $\begin{array}{l}89 \\
(47-200)\end{array}$ & 12 \\
\hline 7 & $\begin{array}{l}30.5 \\
(8-128)\end{array}$ & $\begin{array}{l}2740 \\
(1054-7108)\end{array}$ & $(16-24)$ & $\begin{array}{l}140 \\
(52-390)\end{array}$ & 12 \\
\hline Range & $13-25$ & $4123-14748$ & 12 & $100-180$ & \\
\hline
\end{tabular}

interesting to observe that the same patients also showed similar trends in each of the seven days.

Table 2 shows the cumulative data of plasma alanine aminotransferase, alkaline phosphatase, prothrombin time and serum cholinesterase for the patient group in each day of the study (total 7 days). It can be seen from this table that the values of alanine aminotransferase were very modestly elevated at the beginning of the study and tended to come down towards normal baseline values by the 4th day. On the other hand, serum cholinesterase catalytic concentrations were significantly depressed at the beginning of the study and continued to be low throughout the seven day follow-up period. Prothrombin time showed a similar trend to that of cholinesterase since it was prolonged at the beginning and remained so for the seven days of the study. Alkaline phosphatase did not show any significant change from baseline values throughout the study period.

Table 3 summarizes the results of analysis of serum cholinesterase catalytic concentrations according to the outcomes (fatal or non-fatal) of the sepsis. A significant difference was observed between the catalytic concentrations of cholinesterase in both groups, the level being lower in those who had fatal outcome compared to those who survived the systemic sepsis syndrome.

Tab. 3 Comparison of cholinesterase values in sera from patients with systemic sepsis syndrome

\begin{tabular}{llll}
\hline & No. & $\begin{array}{l}\text { Cholinesterase } \\
(U / 1)\end{array}$ & *P Value \\
\hline Living & 10 & $2906(852-9644)$ & $<0.001$ \\
Dead & 16 & $1484(512-3556)$ & \\
\hline
\end{tabular}

* P value was obtained by Mann-Whitney $\mathrm{U}$ test.

\section{Discussion}

Systemic sepsis syndrome (previously termed septic shock syndrome) is a frequently encountered problem in Intensive Care Unit practice and its incidence may be increasing. While there is little doubt that the main pathogenesis is related to the liberation of endotoxins from Gram-negative bacteria, other mechanisms may also be operational (10). It has been shown previously that early application of aggressive therapy (both supportive and definitive) leads to a reduction in mortality (6). One major aspect of the systemic sepsis syndrome is the hepatic dysfunction which accompanies it. The objective of this study was to examine the use of the serum cholinesterase level as an indicator of hepatic dysfunction in sepsis syndrome.

Our results have shown that there is a decrease in the catalytic concentration of serum cholinesterase in patients with this syndrome. This decrease was maintained throughout the 7 day study period. This is an important observation, since serum cholinesterase seems to show the depression rather early (day 1 ) and continues thereafter, suggesting that it may be a useful corroborative marker supporting the clinical diagnosis. It is interesting to note that the serum cholinesterase has a long half-life in circulation (5). This may suggest that any change in its level should be rather slow after the onset of the sepsis syndrome. However, it is clear from our results that this is not the case, a fact which may be explained by the sensitivity of the biosynthetic mechanism of this enzyme to the effect of systemic sepsis. Other conventional liver function tests such as alanine aminotransferase did not show any reliable pattern of elevation. Prothrombin time, once considered to be a sensitive index of acute liver disease was clearly prolonged yielding 
information similar to that of cholinesterase. This is expected, since most of the coagulation factors are produced by the liver and have short half-lives (about $8-14 \mathrm{~h}$ ), thus showing prolongation in acute liver disease. Plasma alkaline phosphatase, on the other hand, did not show any significant change, an expected observation since biliary obstruction is not a major feature of the systemic sepsis syndrome.

Often, patients with evolving sepsis syndrome may have to undergo emergency surgery of an exploratory or definitive nature. In such cases, suxamethonium (a shortacting depolarising muscle relaxant) is the drug of choice for endotracheal intubation. This drug is dependent on plasma cholinesterase for the timely termination of its action. Fortunately however, the lower catalytic concentration of cholinesterase in these patients is of no clinical significant since as little as $30 \%$ of normal enzyme activity is adequate to prevent unacceptably long duration of action (5). The most common cause of the so-called "suxamethonium apnoea" is not the low catalytic concentrations of the enzyme, but the presence of an atypical enzyme which results from an autosomal recessive gene.

\section{References}

1. Sologub VK, Zaets TL, Tarasov AV, Mordkovitch MR, Yashin AYU. Enteral hyper alimentation of burned patients: the possibility of correcting metabolic disorders by the early administration of prolonged high calorie evenly distributed tube feeds. Burns 1992; 18(3):245-9.

2. Hoffmann RS, Henry GC, Houland MA, Wrisman RS, Weil L, Goldfrank LR. Association between life-threatening cocaine toxicity \& plasma cholinesterase activity. Ann Emerg Med 1992; 21(3):247-53.

3. Bardin PG, van Eden SF, S Joubert JR. Intensive care management of acute organophosphate poisoning. A 7 year experience in the Western Cape. S Afr Med J 1987; 72(9):593-7.

4. Knaus WA, Draper EA, Wagner DP, Zimmerman JE. Apache Il: A severity of disease classification system for acutely ill patients. Crit Care Med 1985; 13:818-29.

5. Atkinson RS, Rushman GB, Lee JA. The muscle relaxants. In: Wright, editor. A synopsis of anaesthesia. Bristol: IOP 1987:255-90.

6. Maunder RJ, Carrico CJ. Sepsis and respiratory failure in the surgical patient: Diagnostic \& therapeutic implications. In: Root RK, Sande MA, editors. Septic shock. New York: Churchill Livingstone, 1985:245-55.
Another aspect of interest was to observe any correlation between the mortality of patients with sepsis syndrome and the catalytic concentration of serum cholinesterase. It is reasonable to assume that patients with more severe sepsis (which was likely to be fatal) should have lower catalytic concentrations of serum cholinesterase than those without mortality. Our results confirmed this. Hence serum cholinesterase seemed to be a reliable prognostic marker in systemic sepsis. If this observation is confirmed in subsequent studies, it carries a clinical implication by helping to predict poor outcome from the outset of the sepsis syndrome in those with low catalytic concentrations and hence such patients will be treated very aggressively from the onset.

This study, by virtue of the limited number of patients involved, is only a preliminary one and further studies involving larger number of patients are needed to substantiate our observations.

\section{Acknowledgement}

We would like to thank Mr. Edwin Mercado and Mr. Arnold Pagayon for typing the manuscript and all ICU Staff of Asir Central Hospital in Abha, Saudi Arabia for the help in collecting the blood samples. We would also like to thank Ms. Kim Barber for helping in the statistical analysis.

7. Hammerschmidt DE, Weaver LJ, Hudson LD, et al. Association of complement activation and elevated plasma C5a with adult respiratory distress syndrome. Lancet 1980; 2:947.

8. Dietz AA, Rubinstein HH, Lubrano T. Colorimetric determination of serum cholinesterase and its genetic variant by the propionylthiocholine-dithio bis (nitrobenzoic acid) procedure. Clin Chem 1973; 19:1309-13.

9. Den Blaauwen DH, Poppe WA, Tritschler W. Cholinesterase (EC 3.1.1.8) with butyrylthiocholine-iodide as substrate: reference depending on age and sex with special effect to hormonal effect and pregnancy. J Clin Chem Clin Biochem 1983; $21: 381-86$

10. Rackow EC, Astiz ME. Pathophysiology and treatment of septic shock. J Am Med Ass 1991; 266:548-54.

Dr A. S. Al-Kassab, MD, PhD, MRCP

Dept. of Internal Medicine

Hurley Medical Center

One Hurley Plaza

Flint, Michigan 48503

U.S.A. 